\title{
Grammatical gender acquisition in sequential trilinguals: Influence of a gendered L1 vs. L2
}

\author{
Megan M. Brown*
}

\begin{abstract}
In an investigation of the acquisition of grammatical gender at the initial stage of L3 acquisition, beginner L3 German learners with L1 English/L2 Spanish or L1 Spanish/L2 English were compared in their ability to identify gender errors in a German grammaticality judgement task. L2 Spanish learners significantly outperformed L1 Spanish learners. Potential explanations for group differences include (1) exclusive transfer of L2 grammatical knowledge at the initial stages of L3, as predicted by the L2 Status Factor Model (Bardel \& Falk 2007), as well as (2) increased metalinguistic knowledge of gender as a result of instruction in the L2.
\end{abstract}

Keywords. Third language acquisition; L3; grammatical gender; German; Spanish; English

1. Introduction. It has long been established in the field of second language (L2) acquisition literature that when adult monolinguals begin to acquire an L2, the grammar of their first language (L1) plays a critical role in the development of the L2 grammar (Flynn 1981; White 2003). This influence of a previously known grammar on the onset of L2 grammatical development is known as "transfer". This early grammatical system formed at the very beginning of L2 acquisition is known as the "initial state". However, when a sequential bilingual begins to learn a third language (L3), is this L3 transfer process the same as the transfer found in L2 acquisition?

Research in the field of third language acquisition suggests that L2 acquisition and L3 acquisition are in fact two distinct phenomena (Flynn et al. 2004). L3 learners have two potential sources of linguistic knowledge from which to draw an initial L3 grammar: the L1 and the L2, and in many cases, grammatical information from one previously known language could be more helpful to the L3 grammar than information from the other language. These two potential transfer sources have led to a debate in the literature regarding the degree to which each previously known language may contribute to the initial L3 grammar, as well as why that language may have been chosen. Research on L3 transfer has outlined a variety of factors that could potentially influence the degree to which each previously known language may contribute to the L3 initial state. These factors include, but are not limited to, order of acquisition, recency of use, L2 proficiency, and typological similarity (Hammarberg 2012).

This experiment investigates the degree to which two of these factors, typological similarity and order of acquisition, influence the acquisition of grammatical gender in L3 German by sequential Spanish/English and English/Spanish bilinguals. The L1/L2 pair of Spanish and English is used due to a dual disparity, in (a) typological similarity to the target L3 and (b) occurrence of the target feature: whereas English is typologically more similar to German, only Spanish has a grammatical gender system similar (but not identical) to that of German. By comparing L1 English/L2 Spanish and L1 Spanish/L2 English speakers in this task, the roles

*I would like to thank Paul Hagstrom and Charles Chang for their guidance throughout this project, as well as Suzanne Flynn and the audience of the 94th Annual Meeting of the Linguistic Society of America for their helpful questions and suggestions. Author: Megan M. Brown, Boston University (mbrown14@bu.edu). 
of typological similarity and order of acquisition in L3 transfer can be distinguished from one another.

\section{Background.}

2.1. MODELS OF L3 TRANSFER. As a result of the array of potential factors that have been found to influence L3 initial state transfer, L3 acquisition researchers have proposed a variety of models in an attempt to predict transfer source(s) at the initial state of L3. While these models are numerous and often make contradicting claims, the majority of them generally fit into one of two categories: wholesale transfer or partial transfer models (Puig-Mayenco et al. 2018).

As their name suggests, wholesale transfer models predict that one language is selected in its entirety to serve as the exclusive source language at the initial stages of L3 acquisition. The non-selected language, meanwhile, is unable to contribute features to the L3 at the initial state, even if those features would be more beneficial than the features of the selected language. However, the claims of individual whole transfer models differ in regards to which factors play a role in determining whether the L1 or the L2 serves as the source language. Some researchers such as Hermas (2010, 2014a, 2014b) and Bardel, Falk and colleagues (Bardel \& Falk 2007, 2012: Falk \& Bardel 2010, Falk \& Bardel 2011; Falk 2017; Falk \& Lindqvist 2019) have suggested that the selection of the source language is based exclusively on order of acquisition. More specifically, Hermas's (2014a) L1 Privilege (L1P) model claims that the L1 holds a privileged status as the speaker's native language and therefore serves as the sole source of transfer for syntactic features. Meanwhile, Bardel \& Falk's (2007) L2 Status Factor Model (L2S) proposes that increased metalinguistic awareness of L2 syntactic features as well as similarities in acquisition experience, such as learning both the L2 and the L3 in adulthood, result in the L2 becoming the exclusive contributor to the L3 initial state.

Meanwhile, the Typological Primacy Model (TPM: Rothman 2010, 2011, 2013, 2015), claims that (psycho)typological similarity between the L3 and one of the speaker's previously known languages, rather than order of acquisition, serves as the determining factor for the selection of source language for the L3 grammar. This selection is based first on perceived lexical similarity between the learner's previously known languages and the L3, followed by phonological similarity, followed by similarities in morphology and syntax.

In contrast to the whole transfer models described above, which claim that one grammar is transferred in its entirety to the exclusion of any other previously known grammar(s), partial transfer models predict that all previously known languages are available to the learner to some degree for the purposes of L3 transfer. In these models, an entire grammatical system does not need to transfer all at once. Instead, individual grammatical properties are transferred as needed. The first researchers to make such a claim were Flynn et al. (2004), who proposed the the Cumulative Enhancement Model of L3 acquisition (CEM: Flynn et al. 2004, Berkes \& Flynn 2012). CEM proposes that all known languages can potentially influence and enhance the development of subsequent language acquisition. However, CEM makes no claims regarding the transfer of unhelpful grammatical features, such as the case for Rothman \& Cabrelli Amaro (2010), where the unhelpful feature of L2 Spanish null subject was found to transfer to L3 French.

In their Linguistic Proximity Model (LPM), Westergaard et al. (2017), further develop the partial-transfer ideas of CEM, in combination with the typological similarity ideas of TPM. 
Similar to Flynn et al.'s (2004) claims with CEM, Westergaard and her colleagues propose that language acquisition is cumulative, and that learners have access to all previously acquired linguistic knowledge, with no part of that previous linguistic competence being blocked at any stage of the acquisition process. They propose that transfer occurs on a property-by-property bases, where facilitative influence is based on structural similarity, similar to TPM, and that non-facilitative influence is the result of learners incorrectly assuming that a linguistic property is shared between a previously acquired language, and the L3. This non-facilitative transfer may occur as a result of a misanalysis the L3 input, or the learner not having sufficient L3 input to make a more accurate assessment.

Structural similarity, however, may not be the only factor involved in partial-transfer. In her Scalpel Model (SM) of L3 acquisition, Slabakova (2017) makes a set of claims that are very similar to LPM in that (1) acquisition happens on a property-by-property bases, rather than wholesale transfer, and (2) non-facilitative transfer is possible. However, Slabakova argues that in addition to the linguistic factors considered by LPM, cognitive and experiential factors can also influence the transfer of a particular feature. While Slabakova notes that her list of potential extralinguistic influencers is certainly on complete, she outlines processing complexity, misleading input, and construction frequency as three of the extralinguistic variables which have been found to influence L3 acquisition success, (Slabakova 2017).

Overall, these different models, which our outlined in Table 1, are in conflict in regards to their predictions for different types of L3 learners with different language backgrounds. Additional research on a variety of linguistic features is needed in order to test the accuracy of various model predictions in actual L3 learners, and one particular feature where this research is somewhat under-explored is the topic of grammatical gender acquisition.

\begin{tabular}{cc} 
Whole Transfer Models & Partial Transfer Models \\
\hline L1 Privilege & Cumulative Enhancement \\
L2 Status & Linguistic Proximity \\
Typological Primacy & Scalpel Model \\
\hline
\end{tabular}

Table 1: Models if L3 Transfer

2.2. GRAMMATICAL GENDER ACQUISITION. Kramer (2015) defines grammatical gender as a system of sorting of nouns into two or more arbitrary classes, gender categories, or groups, which do not necessarily correlate with biological gender in any way. Grammatical gender is distinct from number and case marking within the determiner phrase (DP), and can be expressed via morphological cues on the noun itself, as well as via agreement markers on other parts of the phrase including determiners and adjectives (Kramer 2015). Languages that have a grammatical gender system include Spanish, which has a masculine and a feminine gender category, and German, which has a masculine, a feminine, and a neuter category. An example of grammatical gender marking on determiners in Spanish is found in (1)-(2), and an example grammatical gender marking on determiners in German is found in (3)-(5) below.

(1) El café

The $_{[\mathrm{M}]}$ coffee $_{[\mathrm{M}]}$

(2) La leche

The $_{[\mathrm{F}]} \operatorname{milk}_{[\mathrm{F}]}$ 
(3) Der Kaffe

The $_{[\mathrm{M}]}$ coffee $_{[\mathrm{M}]}$

(4) Die Milch

The $_{[\mathrm{F}]} \operatorname{milk}_{[\mathrm{F}]}$

(5) Das Buch

$\mathrm{The}_{[\mathrm{N}]} \operatorname{book}_{[\mathrm{N}]}$

L2 grammatical gender acquisition researchers such as White et al. (2004) have found evidence that one grammatical gender system can aid in the acquisition of another. This phenomenon has been found to extend beyond acquisition of the two-way masculine/feminine system commonly found in Romance languages. While it has been found that the German gender system can be more difficult for adult learners to acquire than the gender system of Romance languages due to its intertwinement with case and number agreement (Eichler et al. 2012), research has shown that L1 speakers of a Romance language are faster or acquire grammatical gender in L2 German than their L1 English peers (Sabourin 2001).

Meanwhile, L2 gender learners whose L1s do not have a gender feature have been found to be capable of acquiring the gender feature of nouns in gendered L2s, as well as of applying the acquired gender feature to the larger DP, including determiners and adjectives (Oliphant 1998; Granfeldt 2000; White et al. 2004). This successful acquisition of gender has been found not only in grammaticality tests, but also in more natural code-switching research (Cantone \& Müller 2007) and neurolinguistic research (Foucart \& Frenck-Mestre 2010). The degree to which these L2 gender systems are truly native-like in tasks measuring a more "online" or unconscious level of linguistic performance, as opposed to "offline" measures which may be instead reflecting metalinguistic awareness, is still heavily debated (Grüter et al. 2012). However, for the purposes of this study, the question of interest is not whether the grammatical gender developed by these L2-learners is truly native-like, but rather to what degree L1 and L2 gender systems are transferrable to the initial L3 system.

Jaensch (2012) performed some preliminary work related to grammatical gender acquisition in comparing L3 German learners with L1 Spanish/L2 English and L1 Japanese/L2 English in their ability to use phonological gender cues to correctly apply gender to novel nouns. Surprisingly, Jaensch found that the L1 Spanish speakers, who had knowledge of grammatical gender from their L1, performed poorly on this task compared to the native Japanese speakers, who had no previous experience with grammatical gender. These results raise a variety of questions related to (1) whether factors such as order of acquisition or perceived typological dissimilarity inhibited the transfer for grammatical gender knowledge for these participants and (2) the degree to which speakers with knowledge of Spanish as an L2 might perform differently. This study serves as a preliminary investigation into these questions.

2.3. CURRENT STUDY: L3 GRAMMATICAL GENDER ACQUISITION. The current investigation looks to compare L1 English L2 Spanish speakers (referred to here as "E-S-G" to reflect the order of acquisition) and L1 Spanish L2 English (referred to here as "S-E-G") speakers in their acquisition of L3 German grammatical gender, and to compare these results with the predic-tions of the various models of L3 acquisition. The predictions of these various L3 acquisition models are as follows:

Both CEM and LPM, as partial-transfer models, predict learners to have access to all pre- 
viously acquired language knowledge for transfer, which means that regardless of whether Spanish is a learner's L1 or L2, participants are predicted to have access to the gender feature from Spanish in constructing their L3 grammar. While the 'access' to grammatical gender knowledge predicted by partial transfer models does not explicitly predict transfer in all cases, it does suggest that transfer is possible for any learner with previous grammatical gender knowledge, regardless or order of acquisition, and that as a group, L3 German learners with either order of L1/L2 acquisition will out-perform a control group of L1 English L2 German ("E-G") learners with no previous knowledge of grammatical gender on the gender-related portion of the grammaticality judgment task. L1P predicts that only learners with L1 Spanish will have access to the grammatical gender feature from their L1 at the initial stages of L3 German acquisition. Therefore, L1P predicts that, insofar as access to the grammatical gender system of Spanish will be helpful with German gender, the S-E-G participants will perform well in identifying the gender-related errors in the grammaticality judgment task. Meanwhile, E-S-G learners will not have access to the grammatical system of their L2 Spanish during the initial stages of L3 German acquisition. As a result, L1P predicts that S-E-G learners will perform significantly better on a task related to L3 German grammatical gender than E-S-G learners.

L2S meanwhile makes the opposite prediction from L1P, predicting that only E-S-G learners will have access to Spanish grammatical gender in the initial state of L3 German. As a result, L2S predicts that these E-S-G learners will perform significantly better than the S-E-G beginner learners on a test of L3 grammatical gender.

Another possible outcome follows from TPM, which predicts that the language most similar to the L3 will serve as the initial state for the L3 grammar. Under TPM, the two primary linguistic features that influence the selection of a language to serve as the starting point of the L3 are cognates and phonological similarity. Since English is a Germanic language, the high level of shared cognates and phonology makes English much more likely to be selected as the starting language for L3 German in both the L1 English and the L1 Spanish groups. The assumption that English will be perceived to be more typologically similar to German than Spanish is based a statement from Rothman, the author of TPM, that English would be the source language in this particular language combination (Jaensch 2012). According to TPM, therefore, despite understanding grammatical gender in Spanish, both L1 English and L1 Spanish beginner learners will start their L3 grammar without a grammatical gender feature due to their use of English grammar as the initial state of their L3 grammar. As a result, both groups of L3 German leaners would be expected to perform at a level comparable to the E-G control group who have no previous experience with grammatical gender.

Finally, because the Scalpel Model predicts an interaction between a variety of linguistic, cognitive, and experiential factors within an individual speaker as the feature-by-feature construction of the grammar occurs, an analysis of one particular feature such as this study cannot in and of itself disprove or falsify the predictions of SM. A true contradiction to SM would require evidence of wholesale transfer at the initial stage of acquisition. However, any result which demonstrates one group of L3 learners succeeding at the task while the other group is unsuccessful could have implications for SM in relation to the degree to which the various factors addressed in the model interact and compete with each other to influence transfer.

The predictions of each of the discussed models is outlined in Table 2. This experiment looks to investigate the degree to which the grammatical gender knowledge of these two groups of L3 German learners is predicted by each of these models described above. 


\begin{tabular}{lcc} 
& L1 Spanish L2 English & L1 English L2 Spanish \\
\hline CEM \& LPM & Transfer & Transfer \\
L1P & Transfer & No Transfer \\
L2S & No Transfer & Transfer \\
TPM & No Transfer & No Transfer \\
\hline
\end{tabular}

Table 2: Predictions of grammatical gender transfer in sequential Spanish/English bilinguals learning L3 German according to different L3 acquisition Models

\section{Methods.}

3.1. PROCEDURE. The procedure consisted of an online, survey-style task performed independently by participants on their own computers. This task was created using the Qualtrics online survey tool (Qualtrics, 2019). In the task, participants were presented with a total of 36 experimental questions and 32 control questions which were randomized in order. All experimental sentences consisted of a singular noun in the nominative case, along with its definite article. This noun either had the correct definite article, or a definite article marking for the incorrect grammatical gender. An example of a correct and an incorrect sentence are given in (6) and (7), respectively. Additionally, all sentences were in the present tense, and all nouns used were taken from a variety of introductory-level German textbooks. The 32 control sentences consisted of number and case errors.

(6) Die Krawatte ist grün

The $_{[\mathrm{F}]} \mathrm{tie}_{[\mathrm{F}]}$ is green

'The tie is green (correct gender match)'

(7) *Das Baum ist groß

The $_{[\mathrm{N}]}$ tree $_{[\mathrm{M}]}$ is tall

'The tree is tall (gender mismatch masculine noun with neuter determiner)'

Within the set of experimental questions, types of grammatical errors were evenly distributed. For example, there were the same number of masculine nouns incorrectly marked with a feminine determiner as there were masculine nouns incorrectly marked with a neuter determiner determiner. Additionally, sentences were balanced with reference to the similarity between the grammatical gender of the subject noun of the German sentence and the grammatical gender of the corresponding translation noun in Spanish. For example, the word "skirt" is feminine is Spanish (la falda) and masculine in German (der Rock). So in the analysis of a test question containing the noun "Rock" it would be noted that that particular noun has an opposite gender in the participants' other gendered language, Spanish. This variable is referred to as "gender difference". The three possible categories for the gender difference variable were "Same", referring to a case where the German noun and its Spanish translation equivalent had the same grammatical gender, "Opposite", referring to a case where the noun is masculine in one of the two languages and feminine in the other, such as the case of "skirt" described above, and "Neuter" for a case where a noun has the neuter gender in German, and its translation equivalent in Spanish is masculine or feminine.

After completing the grammaticality judgement task, participants were asked to complete a test of German grammatical gender. Participants were presented with a noun in German and 
asked to assign a grammatically gendered determiner to each noun. All German nouns included in the study were tested in this section.

3.2. PARTICIPANTS. Over 200 people responded to an online survey for this experiment. Of those responses, a total of 32 participants ( 20 female, 12 male: mean age $=21.56$ years, age range $=$ 18-47 years) completed the study in its entirety and reported having one of the language backgrounds targeted in this study: (1) Spanish-English or English-Spanish sequential bilinguals learning German as an L3, who reported learning their L2 Spanish after the age of 10, or (2) English monolinguals learning German as an L2. Participants' language backgrounds were verified using the LexTALE vocabulary test (Lemhöfer \& Broersma 2012, Izura et al. 2014) in the participant's L2 (English or Spanish). LexTALE is a brief vocabulary test which asks participants to distinguish true words of the language in question from pseudo-words. A score of $60 \%-80 \%$ on the LexTALE test represents a proficiency level which would be labeled as B2 or "upper intermediate" in the Common European Framework (CEF), while a score of $80 \%$ or higher represents CEF levels of $\mathrm{C} 1$ and $\mathrm{C} 2$, also referred to as lower- and upper-advanced, respectively (Lemhöfer \& Broersma 2012). Only participants who scored in the category of "upper intermediate (B2)" or higher on the LexTALE test for their L2 were categorized as L3 learners for the purpose of this experiment.

All participants qualified as the "beginner" learners of German targeted in this study based on (1) self-reported experience with German coursework, where beginner learners had completed less than two semesters of German coursework and (2) a set of proficiency testing questions which were mixed among the the experimental questions (see Section 3.1). The numbers of participants in each language background group are outlined in Table 3.

\begin{tabular}{lc} 
Language Background & Number of Participants \\
\hline L1 English, L2 Spanish, L3 German (E-S-G) & 11 \\
L1 Spanish, L2 English, L3 German (S-E-G) & 10 \\
L1 English, L2 German (E-G) & 11 \\
\hline
\end{tabular}

Table 3: Numbers of participants in each language group

\section{Results and Discussion.}

4.1. SCORING. Given that all participants in this study were beginner German learners with relatively small German vocabularies, the system for scoring participant responses was designed to reflect participants' knowledge of grammatical gender as a morphosyntactic system, rather than their knowledge of individual lexical items. In order to do this, participants' responses to the grammaticality judgement task were graded with respect to the grammatical gender that they assigned to each of the nouns in question in the German grammatical gender test. For example, if it were the case that a participant identified (7), restated in (8) below, as not containing any errors, and it was also the case that this participant had described the German word "Baum" as a neuter noun, rather than a masculine one, in the German grammatical gender test, then within this participant's own system, the participant is being consistent in regards to the gender of this particular noun. This error would reflect an issue related to the participant's knowledge of the lexical gender of this particular noun, but also reflects that the participant is successfully applying that lexical gender information to the larger morphosyntactic system. Because this research is concerned with participants' acquisition of the larger 
morphosyntactic gender system, not their acquisition of particular lexical items, responses such as the one described above would be marked as "Correct". Using this method, participant responses for each of the 36 questions of interest in the grammaticality judgement task was scored as either "Correct", if it correctly identified a grammatical gender error, or "Incorrect" if it failed to identify that error.

*Das Baum ist groß

The $_{[\mathrm{N}]}$ tree $_{[\mathrm{M}]}$ is tall

4.2. RESULTS. The analysis consisted of a total of 1152 individual sentence judgements. Across all participants with all language backgrounds, $49.5 \%$ of the questions of interest were rated as correct. Trends differed, however, when responses were separated based on language background. The E-S-G participants were the most accurate out of the three language groups, correctly responding to $69.2 \%$ of the questions. The E-G participants meanwhile, correctly responded to $42.4 \%$ of the questions, followed by the S-E-G participants, who correctly responded to $35.8 \%$ of the experimental questions. A chi-square test of independence examining correct identification of a grammatical gender error in relation to the participant's language back-ground found a significant difference between language background groups $\left(X^{2}=37.95\right.$, df $=2, \mathrm{~N}=1152, \mathrm{p}<.0001)$. A summary of all responses separated by language background are represented in Figure 1.

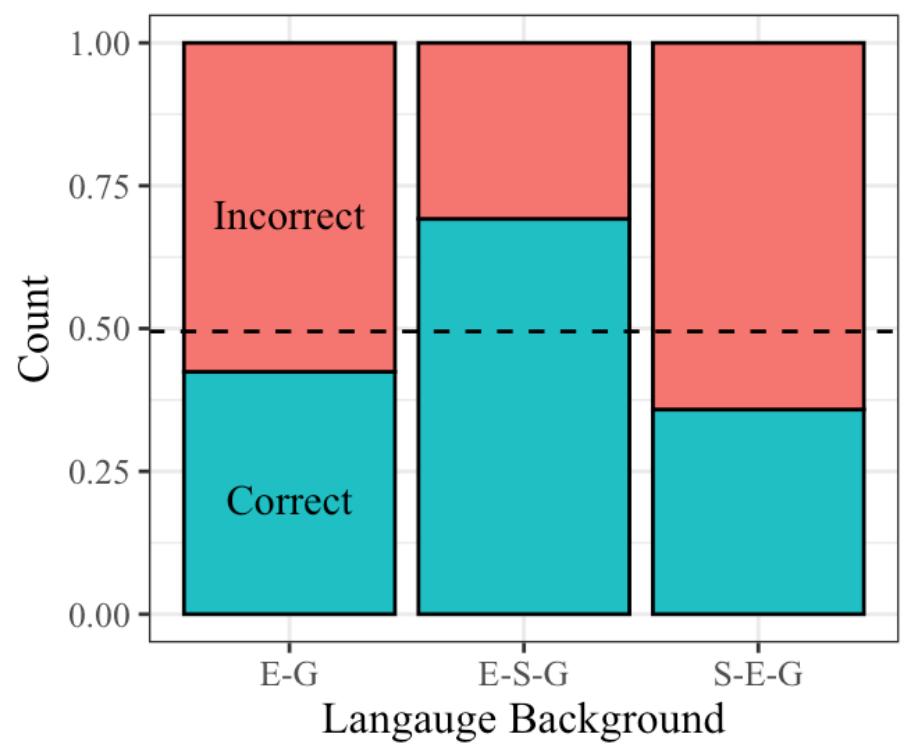

Figure 1: Participant responses by language background

In addition to considering language background, responses were also considered with respect to the gender difference variable described in Section 3.1. As outlined in Figure 2, participants correctly responded to $47 \%$ of the questions containing a noun that fell into the "Same" category, meaning that the German noun in question and its translation equivalent had the same grammatical gender assignment. Additionally, participants correctly responded to $44 \%$ of the questions containing a noun that fell into the "Opposite" gender category, meaning that the noun was masculine in one language and feminine in the other, and $57.0 \%$ of the questions containing "Neuter" nouns. A chi-square test of independence found a significant 


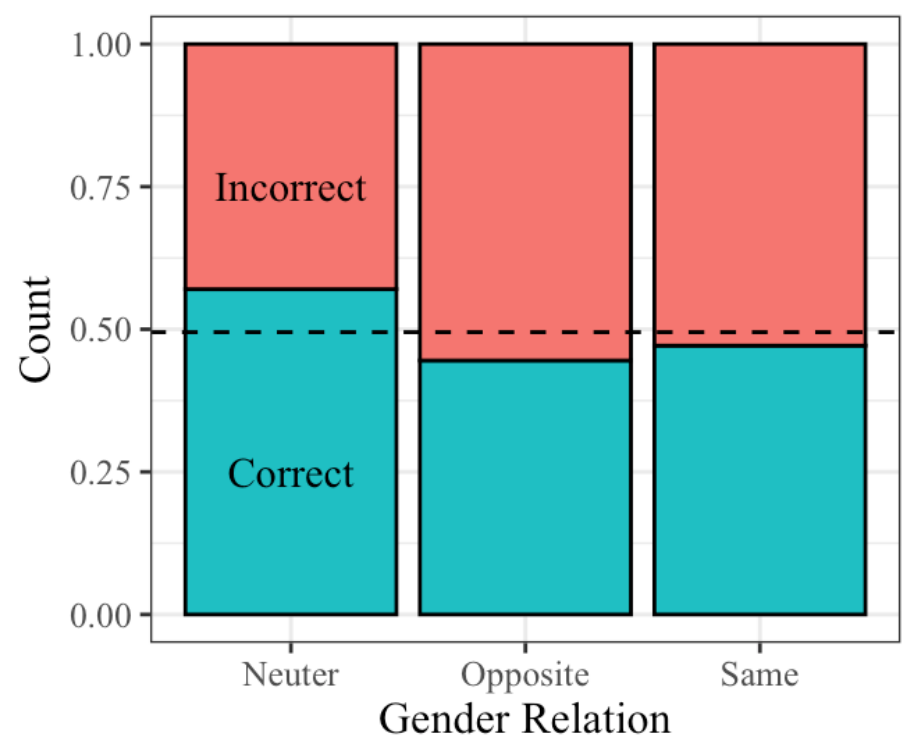

Figure 2: Participant responses by gender difference

difference between correct identification of a grammatical gender error and gender difference $\left(\mathrm{X}^{2}=13.36, \mathrm{df}=2, \mathrm{~N}=1152, \mathrm{p}<.01\right)$.

In order to assess the joint influence of these factors on participants' ability to identify grammatical gender errors, a mixed effects binomial logistic regression was performed using the lme4 package (Bates et al. 2015) in $R$ ( $R$ Core Team 2013). This model, the results of which are outlined in Table 4, considers the random effects of participant and question, as well as the fixed effects of language background (E-G, E-S-G, or S-E-G) and gender difference (Match, Opposite, or Neuter), also testing for an interaction between language background and gender difference. The reference levels for the two categorical variables are E-G and Neuter, and the the "estimate" column in Table 4 represents the likelihood of a change in log odds as compared to the reference levels, where a positive estimate signifies an increase in likelihood and a negative estimate represents a decrease in likelihood. Results of this regression analysis show that participants were significantly more likely to correctly identify an error if they had a language background of E-S-G. The analysis found no other significant effects related to language background. Additionally, participants were significantly less likely to correctly identify a grammatical gender error if the gender mismatch was "Match" or "Opposite". No significant effect of gender match was found in cases where the gender match category was "Neuter". The model found no significant interaction between the predictors language background and gender difference, meaning that it was not the case that any particular language background group was significantly more or less likely to perform well on a particular type of gender difference question.

An $\mathrm{R}^{2}$ for this model was calculated using the MuMIn package (Barton 2009) and states that the random effects of participant and question account for $12.2 \%$ of the variation in the data while the combination of those random effects with the fixed effects of language background and gender mismatch account for $28.7 \%$ of the variation in the data. 


\begin{tabular}{lllll} 
Variable & Estimate & St. Error & z-score & $\operatorname{Pr}(>|\mathrm{z}|)$ \\
\hline Constant & 0.06968 & 0.32352 & 0.215 & 0.82948 \\
Language Background & & & & \\
$\quad$ E-S-G & 1.23305 & 0.45515 & 2.709 & $0.00675 * *$ \\
$\quad$ S-E-G & -0.46995 & 0.45720 & -1.028 & 0.30400 \\
$\quad$ Base $=E-G$ & & & & \\
Gender Difference & & & & \\
$\quad$ Opposite & -0.69501 & 0.29388 & -2.365 & $0.01803 *$ \\
$\quad$ Match & -0.61987 & 0.29290 & -2.116 & $0.03432 *$ \\
$\quad$ Base $=$ Neuter & & & & \\
Interactions & & & & \\
$\quad$ E-S-G*Opposite & -0.08861 & 0.39264 & -0.226 & 0.82145 \\
$\quad$ E-S-G*Match & 0.24465 & 0.39661 & 0.617 & 0.53732 \\
$\quad$ S-E-G*Opposite & 0.30887 & 0.39899 & 0.774 & 0.43886 \\
$\quad$ S-E-G*Match & 0.09688 & 0.40045 & 0.242 & 0.80884 \\
\hline $\mathrm{R}^{2}$ Fixed & 0.122 & & & \\
$\mathrm{R}^{2}$ Total & 0.287 & & &
\end{tabular}

Table 4: Mixed effects logistic regression results

4.3. DisCUSSION. Overall, results demonstrate that participants who had a language background of L2 Spanish out-performed participants with other language backgrounds in their ability to identify grammatical gender errors in L3 German. While the results of this particular study consider on a single grammatical feature, and as a result are unable to make larger claims about the validity of wholesale versus partial transfer models, the results do have implications in relation to individual models of L3 transfer.

In terms of the wholesale transfer models to L3 acquisition, these results would fall in line with the predictions of L2S. Namely, that initial state learners will transfer their L2 grammatical knowledge at the start of L3 acquisition. According to this model, the differences found between the E-S-G participants and the S-E-G participants in this study are the result of the grammatical gender knowledge from L1 Spanish being inaccessible for the S-E-G group, while L2 grammatical gender knowledge was transferrable for E-S-G participants. The predictions of L1P and TPM meanwhile are not reflected in the results of this study.

From a partial transfer perspective, CEM and LPM do not make any claims which could account for the group differences found in this study. The Scalpel Model, however, predicts that extralinguistic factors may inhibit the transfer of individual linguistic features (Slabakova 2017). While Slabakova is relatively vague with respect to what extralinguistic features might inhibit the transfer of a particular grammatical feature, it could be the case that the L2 Spanish participants have some cognitive factor such as increased metalinguistic awareness of grammatical gender, which leads to transfer for the L2 Spanish participants compared to their L2 English peers. In particular, given the relatively low $\mathrm{R}^{2}$ value found in the regression analysis Table 4, it could be the case that some extralinguistic factor correlated with being an S-E-G learning is the cause for the group differences found in this study and could be the cause of the group differences found in this study. This possibility will need to be further explored in future research. 
It should be noted, however, that all of the models discussed in this paper are intended to predict the success of learners at the very beginning of the language learning process, also known as the "initial state". Puig-Mayenco \& Rothman (2019) note that there is a critical difference between true initial state learners, and low-level beginners who have had significantly more exposure to and/or instruction in their L3. While all participants in this study qualified as beginner learners, it is unclear how many of them, if any, would qualify as the true "initial state" learners as defined by Puig-Mayenco \& Rothman.

Given this consideration, an alternative explanation for the results found in this study is that initial transfer of grammatical gender does not occur for any of the L3 learners, regardless of order of previous language acquisition, such as in the case of TPM's prediction outlined in Table 2. In this case, the difference between L1 and L2 Spanish participants found in this study could instead be due to the fact that the L2 Spanish participants have more experience learning grammatical gender in a non-native, classroom context, and as a result, are faster to acquire grammatical gender in a second foreign language than their L1 Spanish peers. So while both groups may have had an initial state grammar with no grammatical gender, the L2 Spanish speakers could be better equipped to learn gender in a foreign language context during one of the early (but not initial) stages of acquisition.

In summary, this work finds that beginner third language learners of German with an L1 English, L2 Spanish background out perform their L1 Spanish L2 English peers in identify grammatical gender errors in German. While current models of L3 acquisition in conflicted in regards to the reasons for this group-based difference, these results emphasize role of order of acquisition in L3 research and set the groundwork for further inquisition into morphosyntactic transfer in L3 German.

5. Conclusions. This work looks to test the predictions of a variety of previously proposed models in their ability to predict the success of sequential English/Spanish and Spanish/English bilinguals in acquiring L3 German grammatical gender. Results found that L3 German learners with a background of L1 English/L2 Spanish out-performed speakers with an L1 Spanish/L2 English background in their ability to identify grammatical gender errors in the provided German sentences. These results suggest some advantage of previous experience with a gendered L2 provides in acquiring L3 grammatical gender, and that this advantage is not available for learners with a gendered L1. It is unclear whether this L2 Spanish advantage in L3 gender acquisition is the result of (1) wholesale transfer of the L2 (2) partial transfer of the relevant features being triggered by extralinguistic factors, or (3) increased metalinguistic awareness and experience with grammatical gender leading to faster L3 gender learning. Future work by this author is currently considering acquisition data from true initial-state learners in order to further investigate these three potential explanations. Additionally, this author's future work will look to further tease apart how the simultaneous acquisition of case and number features which are occurring in parallel to gender acquisition may also play a role in the L3 German DP acquisition process.

Additional further investigation on this topic could investigate (a) the degree to which these findings can be replicated with different language combinations, especially combinations which include more typologically distant languages, (2) the role of additional potentially influential factors not considered in this study such as the participants' language dominance, and (3) whether similar results are found with respect to other features of L3 DP structure, such 
as number, case, and definiteness. These different factors may provide valuable information related to the process of DP acquisition and structure in adult L3 learners.

\section{References}

Bardel, Camilla \& Ylva Falk. 2007. The role of the second language in third language acquisition: The case of Germanic syntax. Second Langauge Acquisition 23. 459-484. http://doi.org/10.1177/0267658307080557.

Bardel, Camilla \& Ylva Falk. 2012. The L2 status factor and the declarative/procedural distinction. In Jennifer Cabrelli Amaro, Suzanne Flynn \& Jason Rothman (eds.), Third language acquisition in adulthood, 61-78. Amsterdam: John Benjamins. http://doi.org/10.1353/lan.2014.0011.

Barton, Kamil. 2009. Mumin: Multi-model inference, r package version 1.43.15. Last retrieved January 23, 2020: http://R-Forge. R-Project. Org/Projects/Mumin/, 2009. https: //cran.r-project.org/web/packages/MuMIn/MuMIn.pdf.

Bates, Douglas, Martin Möchler, Ben Bolker \& Steve Walker. 2015. Fitting linear mixed-effects models using lme4. Journal of Statistical Software 67(1). 1-48. http://doi.org/10.18637/jss.v067.i01.

Berkes, Éva \& Suzanne Flynn. 2012. Further evidence in support of the CumulativeEnhancement Model: CP structure development. In Jennifer Cabrelli Amaro, Suzanne Flynn Flynn \& Jason Rothman (eds.), Third language acquisition in adulthood, 143-164. Amsterdam: John Benjamins. http://doi.org/10.1353/lan.2014.0011.

Cantone, Katja Francesca \& Natascha Müller. 2007. Un nase or una nase? What gender marking within switched DPs reveals about the architecture of the bilingual language faculty. Lingua 118. 810-826. http://doi.org/10.1016/j.lingua.2007.05.007.

Eichler, Nadine, Veronika Jansen \& Natascha Müller. 2012. Gender acquisition in bilingual children: French-German, Italian-German, Spanish-German and Italian-French. International Journal of Bilingualism 17(5). 550-572. http://doi.org/10.1177/1367006911435719.

Falk, Ylva. 2017. On pronouns that drop (out of German). In Tanja Angelovska \& Angela Hahn (eds.), L3 syntactic transfer: Models, new developments and implications, 127-142. Amsterdam: John Benjamins. http://doi.org/10.1075/bpa.5.

Falk, Ylva \& Camilla Bardel. 2010. The study of the role of the background languages in third language acquisition, the state of the art. IRAL, International Review of Applied Linguistics in Language Teaching 43(2). 185-219. http://doi.org/10.1515/iral.2010.009.

Falk, Ylva \& Camilla Bardel. 2011. Object pronouns in German L3 syntax: Evidence for the L2 status factor. Second Language Research 27. 59-82. http://doi.org/10.1177/0267658310386647.

Falk, Ylva \& Christina Lindqvist. 2019. L1 and L2 role assignment in L3 learning. is there a pattern? International Journal of Multilingualism 16(4). 411-424. http://doi.org/10.1080/14790718.2018.1444044.

Flynn, Suzanne. 1981. The effects of first language branching direction on the acquisition of a second language. In W. Harbert \& J. Herschensohn (eds.), Working papers, 50-62. Department of Modern Languages and Linguistics, Cornell University.

Flynn, Suzanne, Claire Foley \& Inna Vinnitskaya. 2004. The Cumulative-Enhancement Model for language acquisition: Comparing adults' and children's patterns of development in 
first, second and third language acquisition of relative clauses. International Journal of Multilingualism 1. 3-16. http://doi.org/10.1080/14790710408668175.

Foucart, Alice \& Cheryl Frenck-Mestre. 2010. Grammatical gender processing in L2: Electrophysiological evidence of the effect of L1-L2 syntactic similarity. Bilingualism: Language and Cognition 14(4). 379-399. http://doi.org/10.1017/S136672891000012X.

Granfeldt, Jonas. 2000. The acquisition of the determiner phrase in bilingual and second language French. Bilingualism: Language and Cognition 3(3). 263-280. http://doi.org/10.1017/S1366728900000377.

Grüter, Theres, Casey Lew-Williams \& Anne Fernald. 2012. Grammatical gender in L2: A production or a real-time processing problem? Second Language Research 28(2). 191-215. http://doi.org/10.1177/0267658312437990.

Hammarberg, Björn. 2012. Third language acquisition. In P. Robinson (ed.), The routledge encyclopedia of second language acquisition, London and New York: Taylor and Francis.

Hermas, Abdelkader. 2010. Language acquisition as computational resetting: verb movement in L3 initial state. International Journal of Multilingualism 7(4). 343-362. http://doi.org/10.1080/14790718.2010.487941.

Hermas, Abdelkader. 2014a. Multilingual transfer: L1 morphosyntax in L3 English. International Journal of Language Studies 8(2). 1-24.

Hermas, Abdelkader. 2014b. Restrictive relatives in L3 English: L1 transfer and ultimate attainment convergence. International Journal of Multilingualism 34(3). 361-387. http://doi.org/10.1080/07268602.2014.898227.

Izura, Cristina, Fernando Cuetos \& Marc Brysbaert. 2014. Lextale-Esp: A test to rapidly and efficiently assess the Spanish vocabulary size. International Journal of Methodology and Experimental Psychology 35(1). 49-66.

Jaensch, Carol. 2012. Acquisition of L3 German: Do some learners have it easier? In Jennifer Cabrelli Amaro, Suzanne Flynn \& Jason Rothman (eds.), Third language acquisition in adulthood,, Amsterdam: John Benjamins. http://doi.org/10.1353/lan.2014.0011.

Kramer, Ruth. 2015. The morphosyntax of gender. Oxford University Press first edition edn.

Lemhöfer, Kristin \& Mirjam Broersma. 2012. Introducing LexTALE: A quick and valid Lexical Test for Advanced Learners of English. Behavior Research Methods 44(2). 325-343. http://doi.org/10.3758/s13428-011-0146-0.

Oliphant, Katrina. 1998. Acquisition of grammatical gender in Italian as a foreign language. Canadian Modern Language Review-Revue Canadienne Des Langues Vivantes 54(2). 239_ 262. http://doi.org/10.3138/cmlr.54.2.239.

Puig-Mayenco, Eloi, Jorge González Alonso \& Jason Rothman. 2018. A systematic review of transfer studies in third language acquisition. Second Language Research 34(1). http://doi.org/10.1177/0267658318809147.

Puig-Mayenco, Eloi \& Jason Rothman. 2019. Low proficiency does not mean ab initio: A methodological footnote for linguistic transfer studies. Language Acquisition http://doi.org/10.1080/10489223.2019.1677668.

Qualtrics. 2019. Qualtrics research suite. Provo, Utah, USA. http://www.qualtrics.com. R Core Team. 2013. R: A language and environment for statistical computing. http://www. R-project.org/. 
Rothman, Jason. 2010. On the typological economy of syntactic transfer: Word order and relative clause high/ low attachment preference in L3 Brazilian Portuguese. International Review of Applied Linguistics in Language Teaching (IRAL) 48. 245-273. http://doi.org/10.1515/iral.2010.011.

Rothman, Jason. 2011. L3 syntactic transfer selectivity and typological determinacy: The Typological Primacy Model. Second Language Research 27. 107-127. http://doi.org/10.1177/0267658310386439.

Rothman, Jason. 2013. Cognitive economy, non-redundancy and typological primacy in L3 acquisition: Evidence from initial stages of L3 Romance. In S. Baauw, F. Dirjkoningen \& M. Pinto (eds.), Romance languages and linguistic theory, 217-247. Amsterdam: John Benjamins. http://doi.org/10.1075/rllt.5.11rot.

Rothman, Jason. 2015. Linguistic and cognitive motivations for the Typological Primacy Model (tpm) of third language (L3) transfer: Timing of acquisition and proficiency considered. Bilingualism: Language and Cognition 18(2). 179-190. http://doi.org/10.1017/S136672891300059X.

Rothman, Jason \& Jennifer Cabrelli Amaro. 2010. What variables condition syntactic transfer? a look at the L3 initial state. Second Language Research 26(2). 189-218.

Sabourin, Laura. 2001. L1 effects on the processing of grammatical gender in L2. EUROSLA Yearbook 1. 159-169.

Slabakova, Roumyana. 2017. The scalpel model of third language acquisition. International Journal of Bilingualism 21(6). 651-665. http://doi.org/10.1177/1367006916655413.

Westergaard, Marit, Natalia Mitrofanova, Roksolana Mykhaylyk \& Yulia Rodina. 2017. Crosslinguistic influence in the acquisition of a third language: The Linguistic Proximity Model. International Journal of Bilingualism 21(6). 666-682. http://doi.org/10.1177/1367006916648859.

White, Lydia. 2003. Second language acquisition and universal grammar. Cambridge: Cambridge University Press.

White, Lydia, Elena Valenzuela, Martyna Kozlowka-Macgregor \& Yan-Kit Ingrid Leung. 2004. Gender and number agreement in nonnative Spanish. Applied Psycholinguistics 25(1). 105-133. http://doi.org/10.1017/S0142716404001067. 